\title{
Antitumor activity of folate-targeted, paclitaxel- loaded polymeric micelles on a human esophageal EC9706 cancer cell line
}

This article was published in the following Dove Press journal:

International Journal of Nanomedicine

5 July 2012

Number of times this article has been viewed

\author{
Wenbin $\mathrm{Wu}^{\mathrm{I}}$ \\ Yonghui Zheng ${ }^{2}$ \\ Rui Wang ${ }^{2}$ \\ Weili Huang ${ }^{3}$ \\ Lei Liu ${ }^{2}$ \\ Xiuli $\mathrm{Hu}^{2}$ \\ Shi Liu ${ }^{2}$ \\ Jun Yue ${ }^{2}$ \\ Ti Tong' \\ Xiabin Jing ${ }^{2}$ \\ 'Department of Thoracic Surgery, \\ Second Hospital of Jilin University, \\ Changchun, ${ }^{2}$ State Key Laboratory \\ of Polymer Physics and Chemistry, \\ Changchun Institute of Applied \\ Chemistry, Chinese Academy of \\ Sciences, Changchun, ${ }^{3}$ Department \\ of Gastroenterology, the Affiliated \\ Hospital of Beihua University, \\ Jilin, China
}

Background: Esophageal cancer is recognized as one of the most refractory pernicious diseases. In addition, it is an aggressive malignancy with a propensity for local progression and distant dissemination. Because of the poor long-term prognosis for patients with esophageal cancer, increasing attention has focused on the integration of targeted agents into current therapeutics. Nevertheless, there have been few studies reported concerning the therapeutic efficacy of paclitaxel-conjugated polymeric micelles in human esophageal cancer in vivo. Therefore, the aim of this research was to investigate the tumor inhibition effect of composite micelles containing folic acid and paclitaxel on the human esophageal EC9706 cancer cell line.

Methods and results: Intravenous administration of folate-targeted, paclitaxel-loaded micelles was demonstrated to be more efficient in inhibiting subcutaneous xenograft tumors and extending the survival rate of tumor-bearing nude mice than free paclitaxel and plain paclitaxel micelles at an equivalent paclitaxel dose of $20 \mathrm{mg} / \mathrm{kg}$, which was further backed up by flow cytometry, TUNEL, and expression of apoptosis-related proteins, including $\mathrm{Bax}, \mathrm{Bcl} 2$, and caspase 3 in this study.

Conclusion: The folate-mediated paclitaxel-loaded polymeric micelle is a promising agent for the treatment of human esophageal cancer.

Keywords: esophageal cancer, folate, paclitaxel, polymer-drug conjugate, targeted drug delivery

\section{Introduction}

Esophageal cancer continues to be a lethal disease, with the majority of patients presenting at an advanced stage ${ }^{1}$ and optimal therapy for patients with resectable tumors remaining unclear. The 5-year survival rate for all patients with esophageal cancer is only $17 \%$, with better survival for local (33.7\%) and regional (16.9\%) disease compared with distant $(2.9 \%)$ disease at presentation. ${ }^{2}$ Surgery is the only potentially curative treatment modality, but local recurrence rates after surgical resection are high due to systemic disease. ${ }^{3,4}$ Moreover, patients with unresectable esophageal cancer are often managed with definitive chemoradiotherapy, with long-term survival rates of $20 \%-25 \%$. $^{5,6}$

In order to improve the poor prognosis, ${ }^{7}$ many strategies have been implemented to develop effective regional and systemic therapies, and survival may be prolonged by the addition of systemic chemotherapy to surgical resection in order to target micrometastases. ${ }^{8}$ Paclitaxel has been found to be efficacious in the treatment of esophageal cancer, with pathologic complete response rates ranging from $20 \%$ to $60 \%$, but accompanied by increased systemic toxicity. ${ }^{9-13}$ To date, paclitaxel-loaded polymeric micelles have received attention because of their nanoscale formulation 
and controlled release of paclitaxel, and have demonstrated significant antitumor activity in patients with metastatic breast, lung, and gastric cancer. When encapsulated into micelles, paclitaxel can reach a solid tumor site via the enhanced permeability and retention effect and maintain an effective therapeutic concentration for a longer period of time. Furthermore, the unique core-shell architecture of polymeric micelles might enable prolonged circulation in the blood and preferential accumulation in solid tumors for passive drug targeting. ${ }^{14}$ The antitumor activity of a paclitaxelincorporating micellar nanoparticle (NK105) was shown to be more efficacious than pure paclitaxel. ${ }^{15} \mathrm{~A}$ polymeric paclitaxel micelle (Genexol-PM) showed a 59\% response rate and a median time to progression of 9 months, ${ }^{16}$ which seems to be promising for treatment of metastatic breast cancer. Paclitaxel poliglumex (PPX, CT-2103), a polymer-drug conjugate of paclitaxel and poly-L-glutamic acid, was designed and the PPX was found to accumulate in tumor tissue, followed by cathepsin B-mediated release of paclitaxel. ${ }^{17}$ Moreover, novel free poly(L- $\gamma$-glutamylglutamine) (PGG)-PTX conjugate nanoparticles were developed and showed an effective tumor growth inhibitory effect in a mouse model. ${ }^{18}$ Another novel biodegradable deoxycholic acid-O-carboxymethylated chitosan-folic acid conjugate (DOMC-FA) was used to form micelles for encapsulating paclitaxel, and folic acidmicellar paclitaxel (DOMC-FA/PTX) showed increased uptake in MCF-7 cells, with stronger cytotoxicity compared with plain micelles. ${ }^{19}$ In addition, Werner et al engineered a folic acid-targeted nanoparticle encapsulating paclitaxel as a chemotherapeutic agent and radioisotope yittrium-90 as a radiotherapeutic agent, while the folate receptor was utilized as the targeting ligand, and displayed great potential for the treatment of peritoneal metastasis from ovarian cancer. ${ }^{20}$

However, to the best of our knowledge, there has been little work reported on the study of therapy using folatetargeted paclitaxel-conjugated polymeric micelles for human esophageal cancer in vivo. Folic acid binds to the folate receptor at the cell surface with very high affinity, and is internalized by receptor-mediated endocytosis. ${ }^{21}$ Furthermore, the folate receptor is overexpressed by carcinomas of the kidney, brain, lung, and breast but has very restricted expression on most normal tissues. ${ }^{22}$ Moreover, the folate receptor was reported to be overexpressed on human esophageal cancer cells. ${ }^{23}$ In our previous work, the folate was attached to a triblock copolymer, methoxy-poly(ethylene glycol)-b-poly (L-lactide)-b-poly(L-lysine), ${ }^{24-27}$ and preferred uptake by HeLa cells and accumulation in mouse hepatoma H22 xenograft tumors were observed. In this research, it was attached to [MPEG-b-P(LA-co-DHP)] while paclitaxel was conjugated with MPEG-b-P(LA-co-MCC), and the two micelles were coassembled into composite micelles containing folic acid and paclitaxel. A series of evaluation studies was performed with a view to elucidating the therapeutic potential of these polymeric micelles for human esophageal cancer. Encouragingly, the mice in the FA-M(PTX) group showed obvious tumor growth inhibition and had significantly prolonged survival compared with conventional paclitaxel and paclitaxel micelles. The enhanced efficacy of FA-M(PTX) is most probably on account of the effective process of folate receptor-mediated endocytosis, although its content is only $1.4 \mathrm{wt} \%$. Therefore, folate-conjugated micelles are worthy of further evaluation for clinical application.

\section{Materials and methods Materials}

In this study, two amphiphilic block copolymers of folic acid-polymer conjugate [MPEG-b-P(LA-co-DHP/FA)] and paclitaxel-polymer conjugate [MPEG-b-P(LA-co-MCC/ PTX), in short, $\mathrm{M}(\mathrm{PTX})]$ were prepared, and the micelles loaded with folic acid and paclitaxel [FA-M(PTX)] were prepared by coassembling a folic acid-polymer conjugate and $\mathrm{M}$ (PTX) with a mass ratio of $1: 9$, as previously described in our laboratory. ${ }^{28,29} \mathrm{MCC}$ and DHP represent trimethylene carbonate units with pendant carboxyl and dihydroxyl groups, respectively.

\section{Cell culture}

The human esophageal EC9706 cancer cell line was obtained from the Shanghai Cell Center of Chinese Academy of Medical Science and was cultured with folic acid-free RPMI 1640 medium (Sigma-Aldrich Inc, St Louis, MO) in a humidified incubator (Sanyo, Japan) containing $5 \% \mathrm{CO}_{2}$ at $37^{\circ} \mathrm{C}$.

\section{MTT assay}

The cytotoxicity of paclitaxel, M(PTX), and FA-M(PTX) in EC9706 cells was determined by MTT assay, and the cells were plated at $5 \times 10^{3}$ cells per well in a 96-well plate with $1 \%$ penicillin and streptomycin in a $5 \% \mathrm{CO}_{2}$-humidified atmosphere at $37^{\circ} \mathrm{C}$. The following day, the medium was renewed by folic acid-free RPMI 1640 and the cells at logarithmic phase were treated with drugs of gradient concentrations. Control cells were treated with an equal volume of RPMI 1640 without paclitaxel. At the desired experimental time points (24, 48, and 72 hours), an MTT assay was performed, as reported elsewhere. ${ }^{30}$ The inhibition rate was calculated as 
$\left[1-\left(\mathrm{OD}_{\text {exp }}-\mathrm{OD}_{0}\right) /\left(\mathrm{OD}_{\text {con }}-\mathrm{OD}_{0}\right)\right] \times 100 \%\left(\mathrm{OD}_{0}\right.$, average optical densities of blank wells for data correction).

\section{Annexin V/propidium iodide double-stain assay}

In flow cytometry analysis, EC9706 cells were seeded into a 6 -well plate with $1 \times 10^{5}$ cells per well and the drugs were added into the wells 16 hours later at the final equivalent paclitaxel concentration of $5 \mu \mathrm{g} / \mathrm{mL}$. Apoptosis-type cell death of tumor cells was detected after incubation with the drugs for 24, 48, and 72 hours, respectively. Briefly, the cells were harvested and resuspended with phosphate-buffered saline, and apoptotic cells were identified using a FITClabeled Annexin V/propidium iodide apoptosis detection kit (Kai-ji Co, Ltd, Nanjing, China). The analysis was performed using a FACS Calibur flow cytometer (Becton Dickinson Co, Ltd, Franklin Lakes, NJ). Cells in the early stages of apoptosis were positively stained only with Annexin V (lower right quadrant, Annexin V-positive/propidium iodide-negative), whereas cells in late apoptosis were positively stained with both Annexin V and propidium iodide (upper right quadrant, Annexin V-positive/propidium iodide-positive) and the apoptosis of one sample was given as the sum of early and late apoptosis. Prior to the cell uptake studies, micelles containing rhodamine $\mathrm{B}(\mathrm{RhB})$ were tested to be stable $\left(37^{\circ} \mathrm{C}\right)$ in the medium, phosphate-buffered saline, and in fetal bovine serum.

\section{In vitro cell uptake analysis}

Confocal laser scanning microscopy (CLSM) and flow cytometry assay were performed to evaluate the role of folic acid-folate receptor-mediated endocytosis in cell uptake and internalization of micelles by EC9706 cells. In order to facilitate detection by CLSM or flow cytometry, the folic acid-conjugated or folic acid-free micelles were labeled with $\mathrm{RhB}$ according to the reference. ${ }^{31}$ The former is represented as FA-M(RhB) and the latter as $\mathrm{M}(\mathrm{RhB})$. For CLSM, the cells were seeded into 6-well plates with $10^{5}$ cells per well as a monolayer on a clean coverslip in folate-free RPMI 1640 medium overnight followed by incubation with free $\mathrm{RhB}, \mathrm{M}(\mathrm{RhB})$, or FA-M(RhB) with an $0.2 \mathrm{mM}$ equivalent of $\mathrm{RhB}$ for one hour at $37^{\circ} \mathrm{C}$. Free folic acid was expected to result in saturation and blockade of the folate receptor, so the same experiment was repeated using a medium containing $1 \mathrm{mM}$ of free folic acid to determine the effect of blockade of the folate receptor. After one hour of coincubation, the supernatant was carefully removed and the cells were washed three times with ice-cold phosphate-buffered saline. Subsequently, the cells were fixed with $1 \mathrm{~mL}$ of $4 \%$ paraformaldehyde for 15 minutes at room temperature, followed by washing with phosphate-buffered saline for three times. For labeling of the nucleus, the fixed cells were stained with $1 \mu \mathrm{g} / \mathrm{mL}$ of DAPI (4'-6-diamidino-2-phenylindole, Sigma Chemical Co, St Louis, MO) for 15 minutes at room temperature, followed by carefully rinsing with phosphate-buffered saline. The coverslips with fixed cells were placed on a glass microscope slide and the samples were analyzed using CLSM on a Zeiss LSM 510 (Zurich, Switzerland) with a confocal plane of $300 \mathrm{~nm}$. DAPI and RhB were excited at $340 \mathrm{~nm}$ and $555 \mathrm{~nm}$, with emissions at $488 \mathrm{~nm}$ and $580 \mathrm{~nm}$, respectively.

For flow cytometry analysis, the EC9706 cells were seeded in 6-well plates at $10^{5}$ cells per well without coverslips overnight, followed by incubation with $\mathrm{M}(\mathrm{RhB})$ or FA-M(RhB) the same as the CLSM assay, and then harvested using $0.25 \%$ trypsin-ethylenediamine tetra-acetic acid. The suspensions were centrifuged at $1000 \mathrm{rpm}$ for 5 minutes at $4^{\circ} \mathrm{C}$ and washed twice with cold phosphate-buffered saline, then resuspended in phosphate-buffered saline. Fluorescence histograms were recorded using a BD FACS Calibur flow cytometer (Becton Dickinson).

\section{Evaluation of antitumor effect and survival analysis}

Male athymic nude mice (nu/nu) 6-8 weeks of age and weighing 18-22 $\mathrm{g}$ were obtained from the Institute of Laboratory Animals, Chinese Academy of Medical Science, and raised in a specific pathogen-free facility for in vivo experiments following Chinese government guidelines. All animal procedures were approved and controlled by the local ethics committee and carried out according to the guidelines of Chinese law concerning protection of animal life. The nude mice were housed at $22^{\circ} \mathrm{C}$ with a relative humidity of $40 \%-60 \%$ and a 12 -hour light/12-hour dark cycle. The EC9706 cells cultured in vitro were collected and adjusted in $0.9 \%$ saline. Next, $1 \times 10^{6}$ live EC9706 cells $(0.1 \mathrm{~mL})$ were injected into each mouse subcutaneously at the mammary fat pad near the left armpit. The xenografts were visible 7 days after injection of the cells. Tumor volume (V) was calculated by the formula:

$$
\mathrm{V}=1 / 2\left(\text { length } \times \text { width }^{2}\right)
$$

On day 11 after injection of the cells, 57 nude mice (weighing $20.7 \pm 1.9 \mathrm{~g}$ ) with locally isolated tumors (diameter $5.5-6.5 \mathrm{~mm}$ ) were selected and randomly divided into four groups for evaluation of tumor inhibition. The mice were 
injected via the tail vein with $0.4 \mathrm{~mL}$ of saline (control) or $0.4 \mathrm{~mL}$ of saline solutions containing paclitaxel, M(PTX), and FA-M(PTX), respectively, with an equivalent paclitaxel dose of $20 \mathrm{mg} / \mathrm{kg}$. Then, on day 13 after injection of cells, 101 mice (weighing $20.8 \pm 1.7 \mathrm{~g}$ ) with locally isolated tumors (diameter of 6.5-7.4 mm) from the rest models were randomly divided into four groups and treated similarly, as above. The mouse survival rate in each group was recorded daily and censored at day 75 after drug administration.

\section{Detection of apoptosis in xenograft tumors}

On day 12 after drug administration, all 57 mice were sacrificed under anesthesia and the xenografts were excised completely and weighed for evaluation of tumor inhibition. Each fresh tumor was then cut into two equal parts. One part was prepared as a cellular suspension and washed three times in cold phosphate-buffered saline $\left(\mathrm{pH} 7.2-7.4,0^{\circ} \mathrm{C}-4^{\circ} \mathrm{C}\right)$ then resuspended and adjusted to $1 \times 10^{6}$ cells per sample, followed by Annexin V-FITC/propidium iodide double-staining and flow cytometry analysis, similar to the test in vitro. The other part was fixed in 4\% paraformaldehyde for 48 hours at $4^{\circ} \mathrm{C}$, then embedded in paraffin and sectioned by microtome (Rotary Microtome YD-315, China) for TUNEL, immunohistochemistry, and hematoxylin and eosin staining.

For the TUNEL assay, tumor tissue sections ( $4 \mu \mathrm{m}$ in thickness) were stained using a TUNEL kit (terminal deoxynucleotidyl transferase-mediated dUTP nick end labeling, where dUTP designates deoxyuridine triphosphate, Roche Diagnostics GmbH, Germany), which consists of a dUTP labeled by digoxigenin and an antidigoxigenin antibody conjugated with horseradish peroxidase. The assay was carried out in accordance with standard instructions, and the tumor sections were examined under a light microscope to measure the gray values using a Motic Image Advanced 3.2 image analysis system (Jed Pella Inc, Redding, CA). The gray value is a measure of light brightness, expressed as a number from 0 (black) to 255 (white). Generally, higher gray scale values correspond to lower immunoreaction intensities. The gray values of five different locations in the $400 \times$ micrograph of one section were averaged as one sample.

\section{Immunohistochemical examination}

The primary and secondary antibodies were obtained from Beijing Bo'ao Biotechnology Co, Ltd (Beijing, China). In detail, paraffin sections of an excised tumor (4 $\mu \mathrm{m}$ in thickness) were dewaxed for immunohistochemistry following the avidin-biotin-peroxidase method.
After blocking with endogenous peroxidase using $0.3 \% \mathrm{H}_{2} \mathrm{O}_{2}$ and goat immune serum for 15 minutes, the sections were boiled in $10 \mathrm{mM}$ citrate buffer ( $\mathrm{pH}$ 6.0) for 25 minutes, then incubated overnight at $4{ }^{\circ} \mathrm{C}$ with the primary antibody at a dilution of 1:100 of $\mathrm{Bcl} 2$, Bax, and caspase 3, respectively, followed by incubation with biotinylated antirabbit IgG at a dilution of 1:200 for 10 minutes at room temperature followed by incubation with avidin-biotin-peroxidase at a dilution of $1: 100$ for 10 minutes at $22^{\circ} \mathrm{C}$. The peroxidase reaction was visualized with $0.05 \%$ diaminobenzidine and $0.01 \% \mathrm{H}_{2} \mathrm{O}_{2}$, followed by counterstaining with hematoxylin. The specificity of the immunoreaction was tested by preincubation of the antibodies with the corresponding antigenic peptides. The immunohistochemistry pictures were taken under an Olympus BX51 microscope (Olympus Optical Co, Ltd, Tokyo, Japan) and the gray values of the sections were detected in a manner similar to that of the TUNEL assay.

\section{Hematoxylin and eosin staining of tumor slices}

For histology observation, the tumor slices were fixed in $4 \%$ paraformaldehyde dehydrated, embedded in rosin, sectioned (4 $\mu \mathrm{m}$ in thickness), and stained with hematoxylin and eosin (Sigma-Aldrich Inc). Finally, the slices were examined by optical microscopy.

\section{Statistical analysis}

The data are presented as the mean \pm standard deviation $(\bar{x} \pm \mathrm{s})$ and were analyzed using SPSS version 16.0 (SPSS Inc, Chicago IL). Comparison of data between the different groups was tested by one-way analysis of variance. Kaplan-Meier survival plots were generated, and comparisons between the survival curves were made using the long-rank test. $P<0.05$ was considered to be statistically significant.

\section{Results and discussion Preparation of micelles conjugated with folic acid}

In this study, FA-M(PTX) were constructed from two amphiphilic block copolymers, ie, MPEG-b-P(LA-co-DHP/ FA) and MPEG-b-P(LA-co-MCC/PTX), with a mass ratio of $1: 9$, as previously described in our laboratory. ${ }^{28,29}$ For comparison, $\mathrm{M}(\mathrm{PTX})$ were used as the control. The FA$\mathrm{M}$ (PTX) had a spherical shape and an average diameter of about 40-60 nm, identified by dynamic light scattering and transmission electron microscopy (see Supporting Information). The in vitro release behavior of paclitaxel 
from the micelles, which has been studied in our previous work, ${ }^{32}$ is not shown here due to the similar structure of paclitaxel-polymer conjugates. It is noteworthy that folic acid was conjugated with the hydrophobic segment of the block copolymer, which was based on the following considerations: conjugation of folic acid on the hydrophobic segment may reduce the nonspecific uptake of micelles by normal tissue or cells during circulation in the blood; poly(ethylene glycol) (PEG) surface conjugation of folic acid to some extent may perturb the PEG conformation in water and thus reduce the stability of micelles; and the statistically inevitable distributions of folic acid on the micellar interface have been demonstrated to be able to increase endocytosis efficiency by target cell lines in our previous publications. ${ }^{27}$ Moreover, the detailed properties of M(PTX) and FA-M(PTX) are shown in the Supporting Information, including formula, diameter of particles, critical micelle concentration, and drug loading efficiency.

A

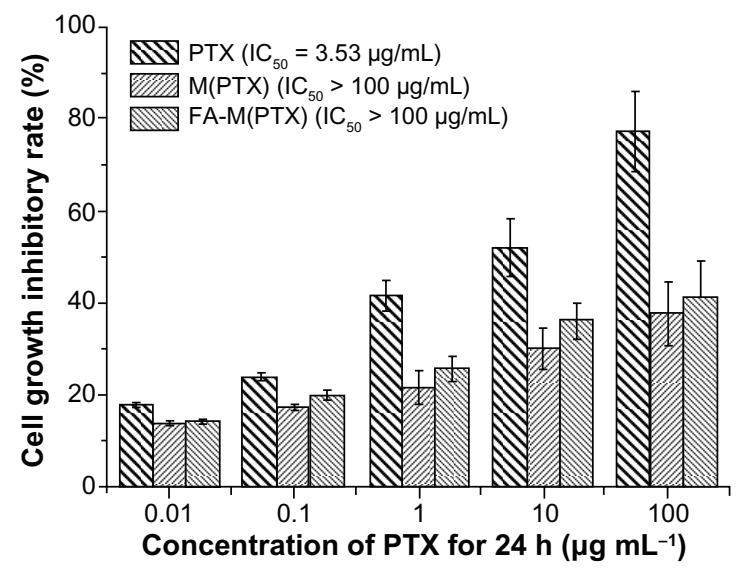

\section{MTT assay}

The cytotoxicity of pure paclitaxel, M(PTX), and FA-M(PTX) in EC9706 cells evaluated by MTT is shown in Figure 1 as a function of equivalent paclitaxel concentration. In most cases, there were no significant differences between the effect of M(PTX) and FA-M(PTX) on EC9706 cells at 24, 48, and 72 hours. Moreover, it is suggested that pure paclitaxel was the most efficacious among the three in vitro at 24 hours, and the $\mathrm{IC}_{50}$ values of the M(PTX) and FA-M(PTX) were $>100 \mu \mathrm{g} / \mathrm{mL}$ compared with that of paclitaxel $(3.53 \mu \mathrm{g} / \mathrm{mL})$. However, the $\mathrm{IC}_{50}$ of the two micelles got closer to that of paclitaxel in a time-dependent manner, and they were $0.10 \mu \mathrm{g} / \mathrm{mL}$ and $0.08 \mu \mathrm{g} / \mathrm{mL}$, respectively, at 72 hours, with obvious similarity to paclitaxel $(0.05 \mu \mathrm{g} / \mathrm{mL})$, which demonstrates theoretically time-dependent release of paclitaxel from the micelles in folic acid-free RPMI 1640 medium. Nevertheless, the folic acidmediated preferential uptake of FA-M(PTX) than M(PTX) is not shown in the cell inhibition assay.

\section{B}

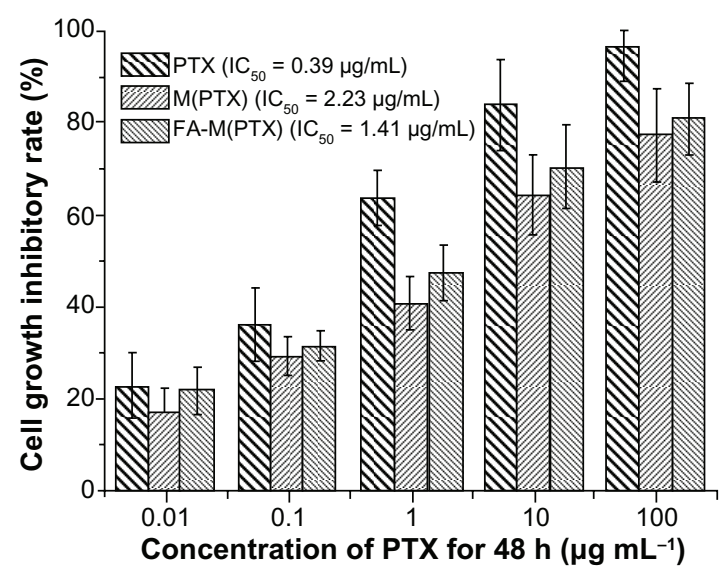

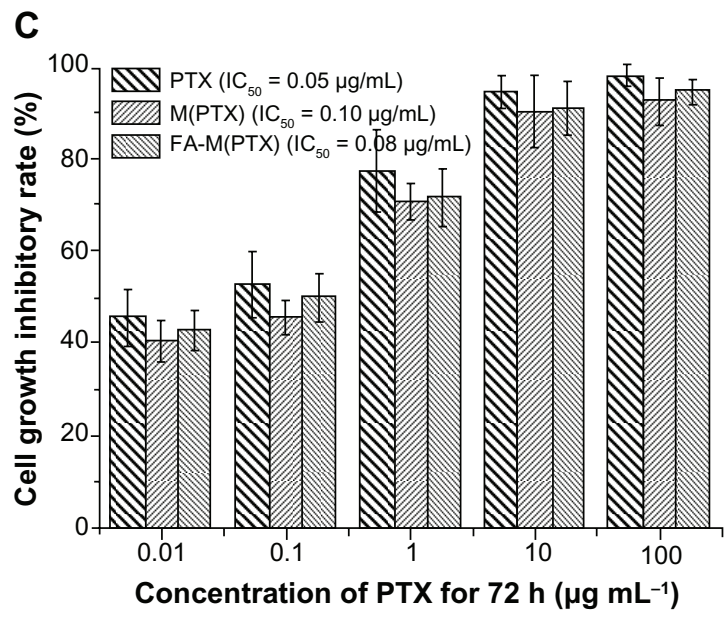

Figure I Cell growth inhibition efficacy of the drug formulations on EC9706 cells after incubation for 24, 48 , and 72 hours. Notes: The equivalent PTX concentrations were $0.01,0.1, I, 10$, and $100 \mu \mathrm{g} / \mathrm{mL}$. Data are presented as the mean \pm standard deviation. Abbreviations: PTX, paclitaxel; M(PTX), paclitaxel-loaded micelles; FA-M(PTX), folate-targeted, paclitaxel-loaded micelles. 


\section{In vitro apoptosis of EC9706 by flow cytometry}

Annexin $\mathrm{V}$ is a $\mathrm{Ca}^{2+}$-dependent phospholipid-binding protein that has a high affinity for membrane phospholipid phosphatidylserine, which translocates from the inner to the outer leaflet of the plasma membrane in the earlier stages of cell apoptosis preceding the loss of membrane integrity. Viable cells with intact membranes exclude propidium iodide, whereas the membranes of dead and damaged cells are permeable to propidium iodide. Therefore, stain with FITC-Annexin $\mathrm{V}$ and propidium iodide can identify early and late apoptotic cells. As shown in Figure 2, the early and late apoptosis rates of the drug groups were significantly higher compared with the control group at 24,48 , and 72 hours. The three drug groups follow the order of $\mathrm{M}(\mathrm{PTX}) \approx$ FA$\mathrm{M}(\mathrm{PTX}) \leq$ paclitaxel at 24 hours, and paclitaxel $<\mathrm{M}(\mathrm{PTX})$ $\leq$ FA-M(PTX) at 48 and 72 hours, respectively.

The MTT and flow cytometry assay both showed that pure paclitaxel, $\mathrm{M}(\mathrm{PTX})$, and $\mathrm{FA}-\mathrm{M}(\mathrm{PTX})$ are toxic to EC9706 cells. Among them, pure paclitaxel is the most efficacious in vitro. This is probably because under in vitro conditions, pure paclitaxel may diffuse into the cancer cells more efficiently than M(PTX) or FA-M(PTX), which is believed to be internalized by cells via endocytosis. Another possibility is that pure paclitaxel is effective once it enters the cells, while the paclitaxel conjugated and trapped in the micelles needs the process of endosome escape and controlled paclitaxel release.

\section{Cell uptake analysis in vitro}

The therapeutic effects of drug-loaded nanoparticles depend on internalization and sustained retention of the nanoparticles by diseased cells..$^{33}$ Although the in vitro and in vivo biologic processes could be very different, an in vitro investigation may provide some preliminary evidence to show the advantages of nanoparticles. ${ }^{34}$ As shown in Figure 3, the red fluorescence was from $\mathrm{RhB}$ or $\mathrm{RhB}$-containing micelles, while the blue fluorescence was from DAPI-stained cell nuclei. Red fluorescence was clearly observed, indicating cellular uptake and internalization of the micelles, and preferential endocytosis of the RhB-conjugated micelles by EC9706 cells over free RhB is shown. Interestingly, the folic acid-conjugated micelles showed markedly enhanced cellular uptake compared with $\mathrm{M}(\mathrm{RhB})$ after one hour of incubation (Figure 3B and C). Moreover, addition of $1 \mathrm{mM}$ of free folic acid led to an obvious decrease in cellular endocytosis of micelles containing folic acid by EC9706 cells (Figure 3C and E). In comparison, there was no statistically significant difference between the cellular uptake of $\mathrm{M}(\mathrm{RhB})$ in either folic acid-free medium or folic acid-containing medium (Figure 3B and D). Furthermore, semiquantitative results are displayed by flow cytometry. Cellular uptake of RhB and RhB-labeled micelles is shown in Figure 3 as a plot of cell counts to fluorescence intensity of RhB. Cells in phosphate-buffered saline without fluorescence of $\mathrm{RhB}$ were set as the controls, and the RhB-stained cell counts for the five groups were $6.1 \% \pm 2.0 \%, 42.8 \% \pm 10.7 \%, 79.1 \% \pm$ $12.5 \%, 41.5 \% \pm 9.1 \%$, and $50.6 \% \pm 7.2 \%$, respectively; a statistically significant difference between group $\mathrm{C}$ and the other groups was shown $(P<0.05)$. Obviously, FA-M $(\mathrm{RhB})$ showed enhanced cellular uptake compared with $\mathrm{M}(\mathrm{RhB})$, which is most probably on account of the effective process of the folate receptor-mediated mechanism, while for $\mathrm{M}(\mathrm{RhB})$, the uptake by cells was merely based on a nonspecific endocytosis mechanism. The result is in agreement with the in vitro apoptosis rate detected by flow cytometry.

\section{In vivo tumor inhibition study}

The time-volume change of the xenografts is shown in Figure 4. On day 12 after drug administration, the mice were sacrificed and the xenograft tumors were excised completely (Figure 5). Their sizes and weights were measured to calculate the tumor inhibition rate (TIR) as follows:

$$
\begin{aligned}
\text { TIR }= & \text { [average tumor weight (volume) of control } \\
& \text { group }- \text { average tumor weight (volume) } \\
& \text { of test group }] / \text { average tumor weight (volume) } \\
& \text { of control group } \times 100 \% .
\end{aligned}
$$

The drug groups showed obvious antitumor efficacy compared with the controls $(P<0.05)$. Moreover, the FA-M(PTX) was superior to the pure paclitaxel and M(PTX) groups $(P<0.05)$ in terms of tumor growth inhibition. Nevertheless, a significantly statistical difference between the pure paclitaxel and M(PTX) group was not observed, as shown in Table 1. Furthermore, the size-based TIR values of the paclitaxel, M(PTX), and FA-M(PTX) groups on day 12 after initial drug administration were about $33.7 \%, 40.9 \%$, and $74.1 \%$, respectively. Their weight-based TIR values were about $21.8 \%, 44.2 \%$, and $61.6 \%$, respectively. FA-M(PTX) showed the best tumor growth inhibitory effect compared with the other formulations of paclitaxel in a time-dependent manner.

\section{Flow cytometry assay for xenograft tumors}

Apoptosis of the esophageal cancer xenografts reflected tumor inhibition efficacy. As shown in Figure 6, apoptosis of the drug groups increased more evidently than that of the control group $(P<0.05)$. Furthermore, the statistical 
A
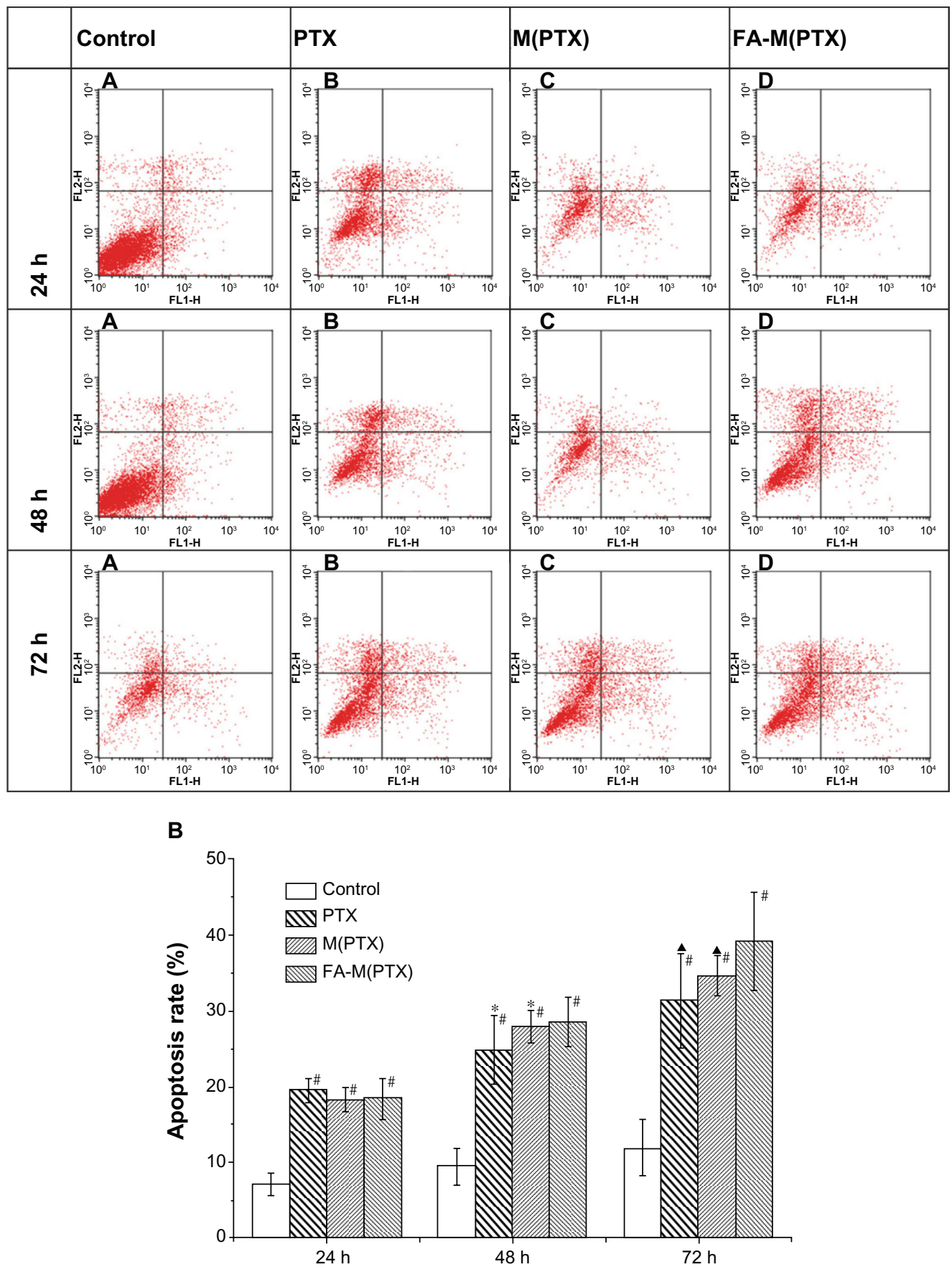

Figure 2 Apoptosis of EC9706 cells detected by flow cytometry at 24, 48, and 72 hours.

Notes: At 24 hours, ${ }^{\# P}<0.01$ versus controls, there was no significant difference between the treatment groups. At 48 hours, ${ }^{\#}<<0.01$ versus controls; $* P<0.05$, compared with FA-M(PTX). At 72 hours, ${ }^{\#} P<0.0$ I, versus controls; ${ }^{\Delta} P<0.0$ I, versus FA-M(PTX).

Abbreviations: PTX, paclitaxel; M(PTX), paclitaxel-loaded micelles; FA-M(PTX), folate-targeted, paclitaxel-loaded micelles.

difference between the FA-M(PTX) group and the other two drug groups was significant $(P<0.05)$. However, there was no obvious difference between the paclitaxel group and the M(PTX) group $(P=0.122)$ on day 12 after initial treatment. Therefore, the FA-M(PTX) displayed the most apoptosisinducing efficacy among the three types of paclitaxel in vivo, which is in accordance with the tumor inhibition evaluation based on weight and volume data for the xenografts.

\section{TUNEL assay of xenograft tumors}

Following histomorphological examination by light microscopy, the slides were assessed as computerized 
A
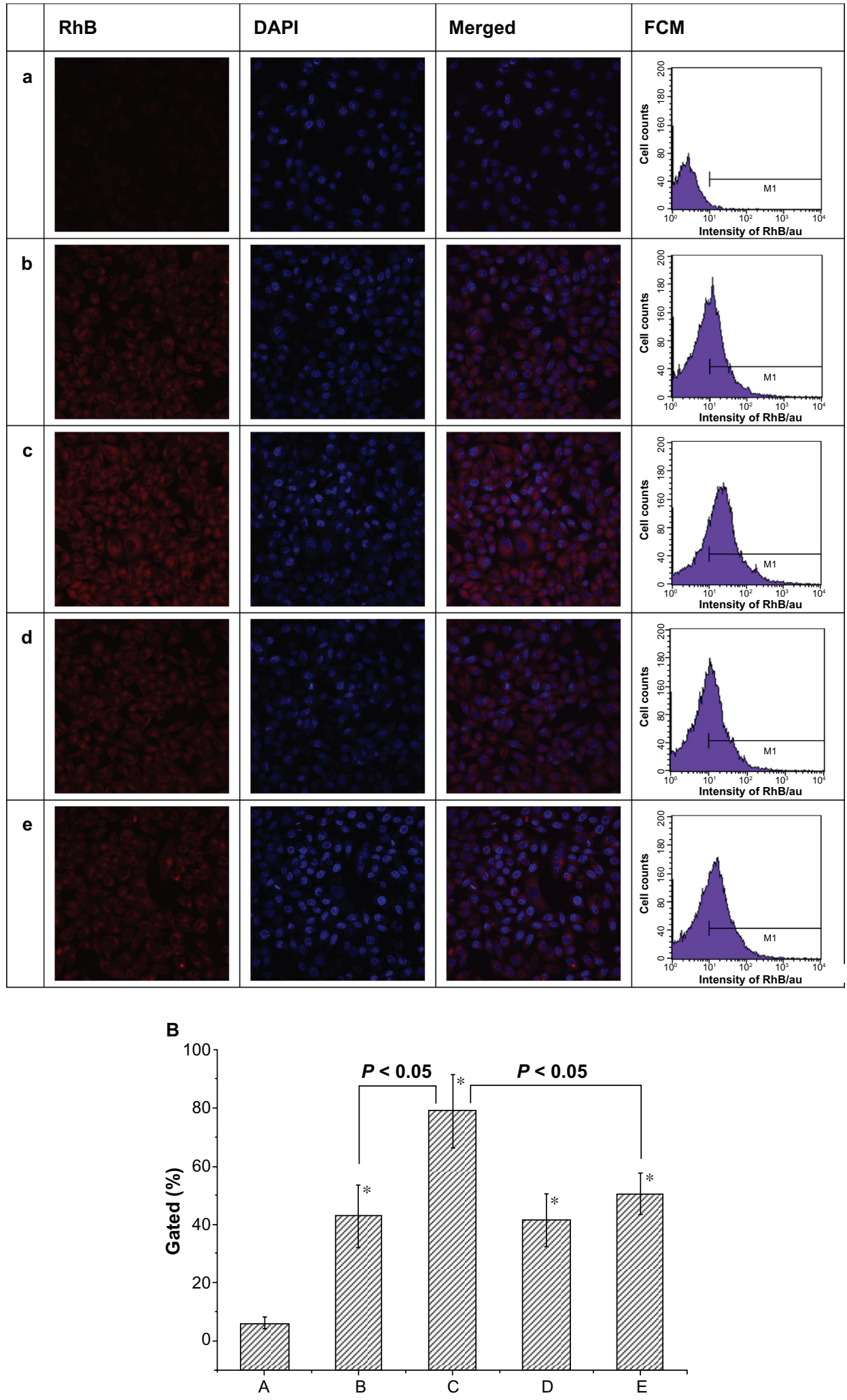

Figure 3 (A) CLSM images and flow cytometry analysis of EC9706 cells incubated with free RhB (a), M(RhB) (b) and FA-M(RhB) (c) in folic acid-free RMPI I640 medium, respectively; (d and e) represent EC9706 cells incubated with $M(\mathrm{RhB})$ and FA-M(RhB) in RMPI I640 medium containing I mM of folic acid, respectively. (B) Statistical data for cellular uptake obtained by flow cytometry.

Note: $* P<0.05$ versus group $A$.

Abbreviations: CLSM, confocal laser scanning microscopy; PTX, paclitaxel; M(PTX), paclitaxel-loaded micelles; FA-M(PTX), folate-targeted, paclitaxel-loaded micelles; FCM, flow cytometry; RhB, rhodamine B. 


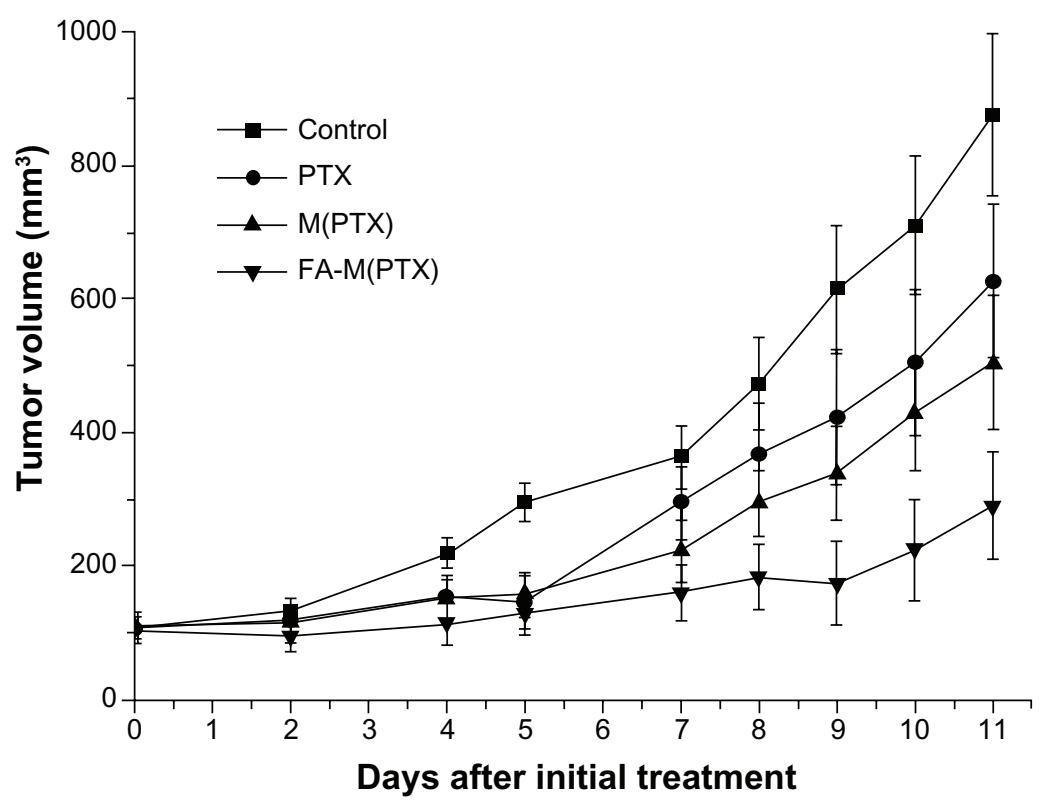

Figure 4 Volume change in xenograft tumors as a function of time.

Abbreviations: PTX, paclitaxel; M(PTX), paclitaxel-loaded micelles; FA-M(PTX), folate-targeted, paclitaxel-loaded micelles.

digital pictures analyzing the mean color intensity (ie, gray values) of tumor tissues using ImagePlus software 3.2. After assessing different tissue areas or cytoplasm within the pictures, a mean gray value per tumor tissue was calculated for further statistical analysis, as reported elsewhere. ${ }^{35}$ The nuclei of the esophageal cancer cells were stained blue by hematoxylin, and the brown granules in the cytoplasm demonstrated apoptosis of cells, as shown in Figure 7A. Statistical analysis of the gray value from the TUNEL assay was performed in Figure 7B, which revealed differences between the drug groups and the control group $(P<0.01)$ on day 12 after intravenous administration. These results suggest that FA-M(PTX) is more effective than paclitaxel or single M(PTX). However, the difference between paclitaxel and M(PTX) was not statistically significant $(P=0.648)$. Because the gray value reveals the immunoreactive intensity of the TUNEL kit, it can be concluded that apoptosis in the FA-M(PTX) group was increased compared with the other groups.

\section{Immunohistochemistry examination}

Apoptosis-related proteins, including Bax, $\mathrm{Bcl} 2$, and Caspase 3 were semiquantitatively evaluated in the xenografts by immunohistochemistry, and the results are shown as gray

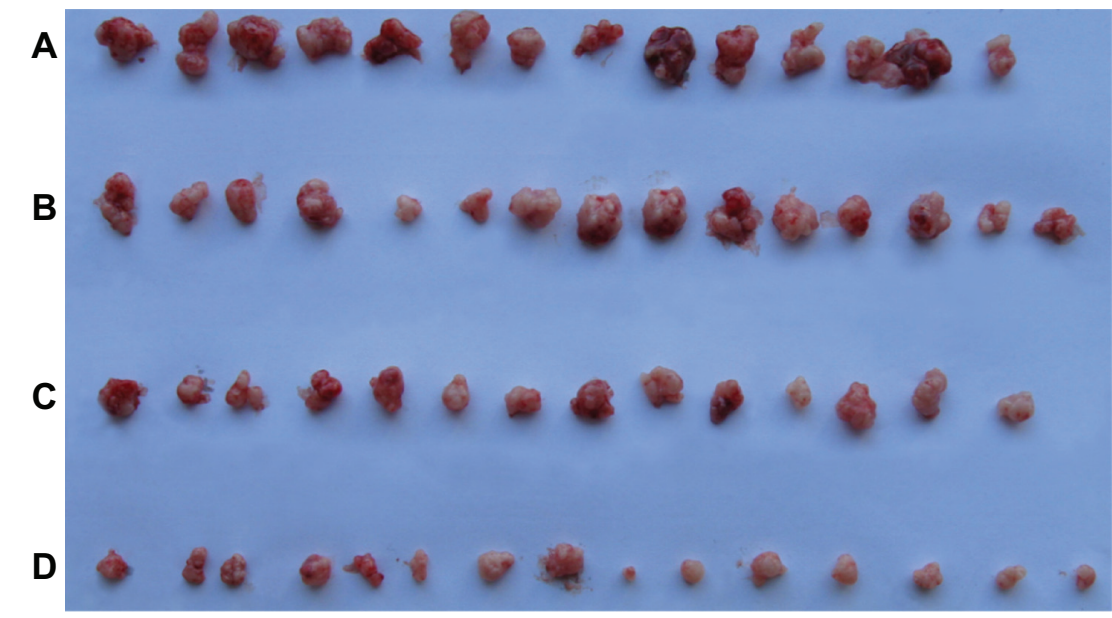

Figure 5 Excised xenograft tumors on day 12 after initial treatment. (A) controls, (B) paclitaxel, (C) paclitaxel-loaded micelles, and (D) folate-targeted, paclitaxel-loaded micelles. 
Table I Mean \pm standard deviation for volume and net weight of EC9706 xenograft tumors on day I2 after initial treatment

\begin{tabular}{|c|c|c|c|c|c|}
\hline Group & $\mathbf{n}$ & Volume $\left(\mathrm{mm}^{3}\right)$ & TIR (\%) & Net weight (g) & TIR (\%) \\
\hline Control & 14 & $592 \pm 264^{4}$ & & $0.54 \pm 0.22^{\wedge}$ & \\
\hline Paclitaxel & 14 & $383 \pm 175^{*, \Delta}$ & 33.7 & $0.42 \pm 0.22^{*, \mathbf{\Delta}}$ & 21.8 \\
\hline $\mathrm{M}(\mathrm{PTX})$ & 14 & $365 \pm 198^{* . \Delta}$ & 40.9 & $0.30 \pm 0.15^{*}$ & 44.2 \\
\hline FA-M(PTX) & 15 & $15 \mid \pm 132 *$ & 74.1 & $0.21 \pm 0.16 *$ & 61.6 \\
\hline
\end{tabular}

Notes: Volume data: $* P<0.01$ versus control; $\Delta P<0.0$ I versus FA-M(PTX); $P=0.8$ I 2 , paclitaxel versus $M(P T X)$; weight data, $* P<0.01$ versus control; $\Delta P<0.0$ I versus FA-M(PTX); $P=0.107$, control versus paclitaxel; $P=0.097$, paclitaxel versus $M(P T X) ; P=0.189, M(P T X)$ versus FA-M(PTX).

Abbreviations: $n$, number of mice; TIR, tumor inhibitory rate; M(PTX), paclitaxel-loaded micelles; FA-M(PTX), folate-targeted, paclitaxel-loaded micelles.

values in the immunohistochemistry photographs using ImagePlus software 3.2. Statistically, for Bax as well as caspase 3 , the gray value of the drug groups was obviously decreased compared with controls $(P<0.05)$, with the lowest gray value in the FA-M(PTX) group compared with the others $(P<0.05)$. Nevertheless, a significant difference between paclitaxel and M(PTX) was not shown in this study $(P=0.859)$. As for $\mathrm{Bcl} 2$, the gray value of the drug groups was significantly increased in comparison with the control group $(P<0.05)$; however, there was no marked difference between the drug groups $(P>0.05)$. It was demonstrated that Bax and caspase 3 expression was upregulated in the drug groups, with the most increased expression in the FA-M(PTX) group. Meanwhile, Bc12 expression was downregulated in the drug groups without any evident difference between them. As shown in Figure 7, the gray values of Bax, caspase 3 , and Bcl 2 indicate a statistically significant difference between FA-M(PTX) and the other two drug groups, which is in agreement with the results of flow cytometry and TUNEL, as well as the tumor volume and weight measurement.

Bax counteracts the antiapoptotic effect of Bcl 2 and initiates a mitochondrial permeability shift transition, leading to activation of downstream apoptosis signaling pathways. ${ }^{36,37}$ Like Bax, Bcl2 has also been investigated as a prognostic indicator of esophageal squamous cell carcinoma, and patients with esophageal squamous cell carcinoma having a complete response were Bcl2 protein-negative. ${ }^{38}$ Low Bax expression was significantly correlated with a lack of complete clinical response and poor overall survival in patients with locally advanced esophageal cancer treated with chemoradiotherapy using 5-fluorouracil and cisplatin..$^{39}$ The downregulation of Bcl2 in cancer cells usually implies apoptosis. ${ }^{40}$ Apoptosis of HeLa cells was induced by upregulating p53 and therefore increased the expression of both $\mathrm{p} 53$ and Bax, while suppressing Bcl2. ${ }^{41}$ Caspase 3 expression correlated with a significant favorable prognosis in primary resected esophageal squamous cell carcinoma, and there was a $25 \%$ 5-year survival rate in caspase 3-positive patients compared with a $6 \% 5$-year survival in caspase 3 -negative patients. ${ }^{42}$ In addition, caspase 3 expression was upregulated in esophageal squamous cell carcinoma compared with normal esophageal epithelium in a Chinese population in a high incidence area, and patients with caspase 3-positive expression had a better prognosis ${ }^{43}$ Furthermore, caspase 3 is activated and upregulated in the apoptotic cell by both extrinsic (death ligand) and intrinsic (mitochondrial) pathways. ${ }^{44,45}$ In this study, the ratio of $\mathrm{Bcl} 2 / \mathrm{Bax}$ is decreased, which is concurrent with the increased apoptosis of EC9706 xenografts in mice when treated with paclitaxel and the micelles, indicating that apoptosis may be mediated via downregulated expression of $\mathrm{Bc} 12$ and upregulated expression of Bax. Furthermore, significant upregulation of caspase 3 expression in EC9706 xenografts in mice in the drug treatment groups compared with the control group was clear, in accordance with prolonged survival of the mice. Immunohistochemistry examination indicated
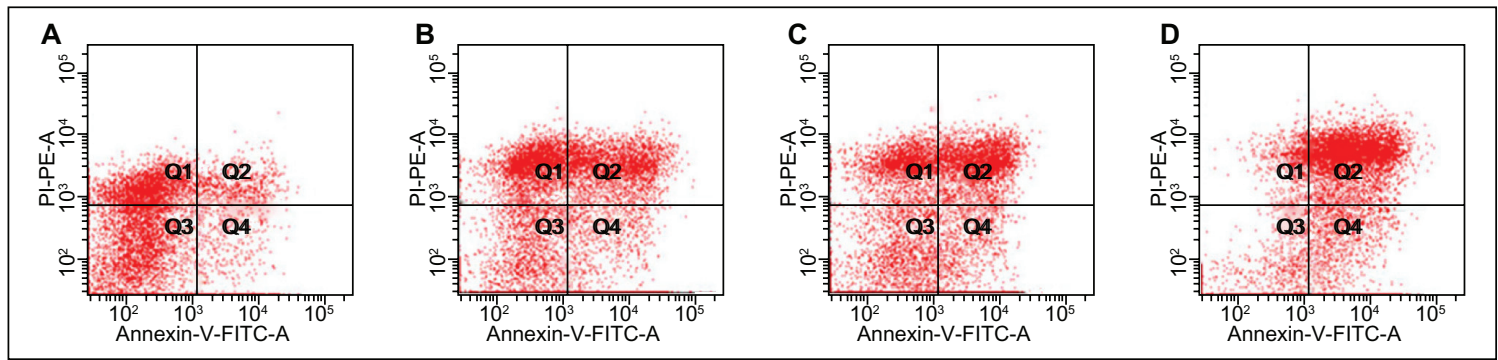

Figure 6 Apoptosis of the xenograft tumors detected by flow cytometry on day 12 after initial treatment. (A) controls, (B) paclitaxel, (C) paclitaxel-loaded micelles, and (D) folate-targeted, paclitaxel-loaded micelles. 


\section{A}

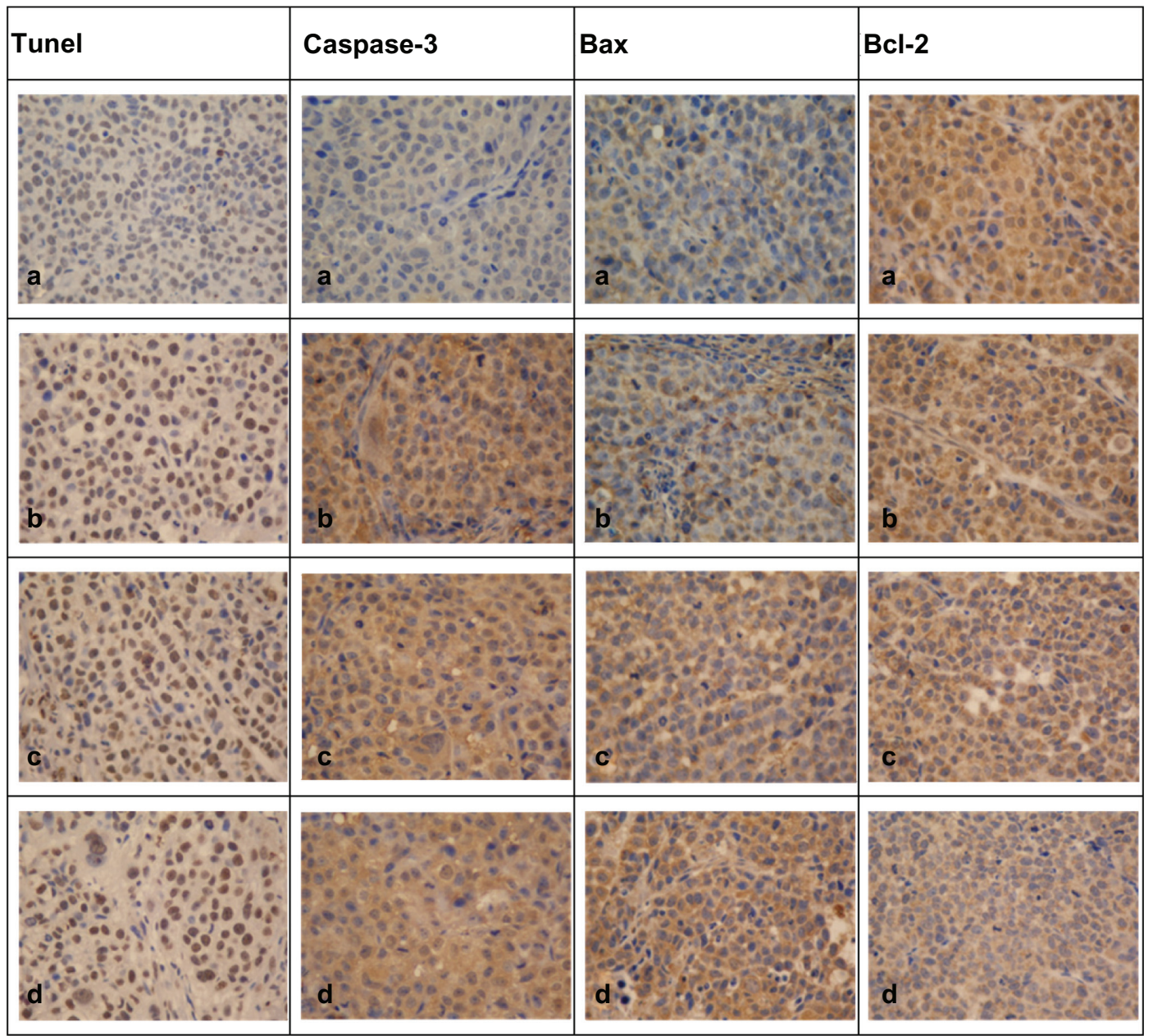

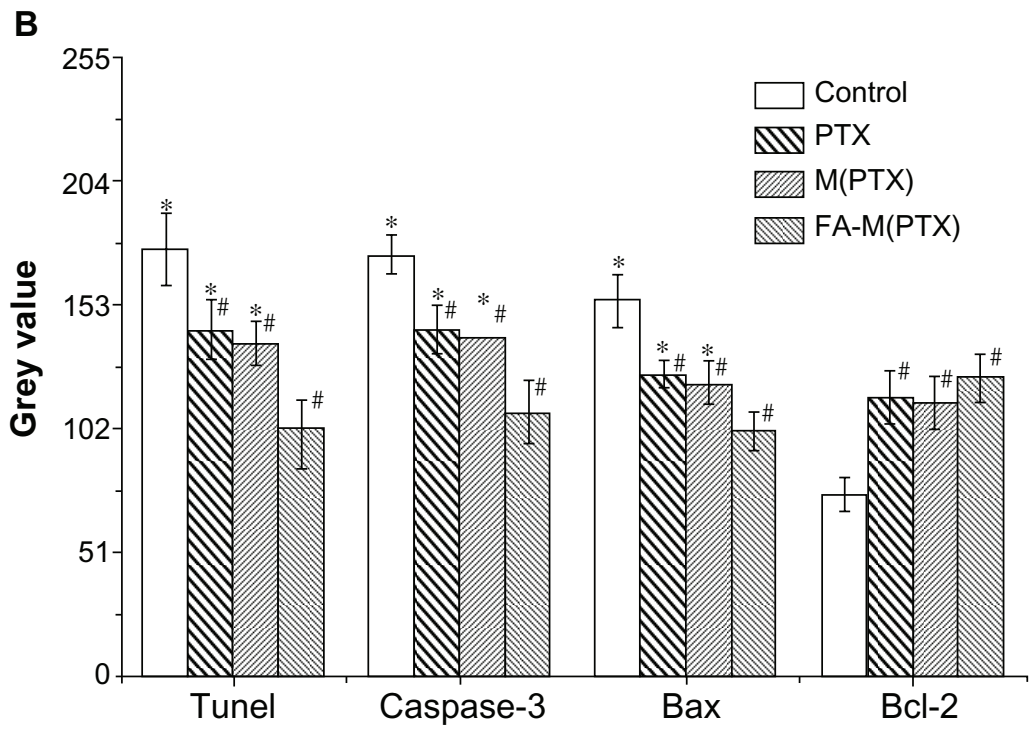

Figure 7 (A) Apoptosis detected by TUNEL and expression of caspase 3, Bax, and Bcl2 detected by immunohistochemistry in xenograft tumors. (a) Controls, (b) PTX, (c) M(PTX), and (d) FA-M(PTX). (B) For TUNEL, ${ }^{*} P<0.05$ versus controls; ${ }^{*} P<0.05$ versus FA-M(PTX); $P=0.648$, PTX versus $M(P T X)$. For caspase 3 , ${ }^{*} P<0.0$ I versus controls; $* P<0.01$ versus FA-M(PTX); $P=0.269$, PTX versus $M(P T X)$. For Bax, ${ }^{*} P<0.05$, versus controls; $* P<0.05$ versus FA-M(PTX); $P=0.859$, PTX versus $M(P T X)$. For $\mathrm{Bcl}-2$, $\# \mathrm{P}<0.05$ versus controls.

Abbreviations: $n$, number of mice; PTX, paclitaxel; M(PTX), paclitaxel-loaded micelles; FA-M(PTX), folate-targeted, paclitaxel-loaded micelles. 
that treatment with paclitaxel led to upregulation of Bax and caspase 3 and downregulation of $\mathrm{Bcl} 2$, and the extent of downregulation or upregulation caused by FA-M(PTX) was greater than that caused by paclitaxel and M(PTX). In other words, the expression of these proteins is in parallel with the apoptosis caused by paclitaxel, and the relationship between protein expression and tumor apoptosis is applicable in the case of EC9706 cancer-bearing nude mice.

\section{Histopathological examination}

The slices for hematoxylin and eosin staining were obtained along the margin of the excised tumor xenografts where the blood supply was theoretically better than that within the tumor. As shown in Figure 8, the areas of tissue necrosis (indicated by straight arrows) significantly increased in the FA-M(PTX) group compared with the others, which further demonstrated the enhanced antitumor efficacy of micelles containing the folic acid ligand. In addition, a few neutrophils, lymphocytes, and macrophages were found around or within the necrotic area of the tumor tissue sections, which is evidence of phagocytosis and a clearance reaction after cell apoptosis. ${ }^{46}$

\section{Survival analysis}

A total of 101 nude mice were randomly divided into four groups and used for survival analysis. The subcutaneous tumors were measured every two days. As shown in
Figure 9A, the drug groups showed significant tumor growth inhibition efficacy, in agreement with Figure 4. On day 75 after initial treatment, when the survival analysis was censored, all mice in the control and paclitaxel groups had died, while three survived in the M(PTX) group and nine survived in the FA-M(PTX) group, with the survival rate at 75 days being $0 \%, 0 \%, 12 \%(3 / 25)$, and $34.6 \%(9 / 26)$, respectively. The Kaplan-Meier survival curve is shown in Figure 9B. The median/mean survival time of the groups was compared using the log-rank test (Table 2). The difference in survival time between the FA-M(PTX) and the other groups was statistically significant $(P<0.05)$. In particular, the tumor-bearing models in the drug groups showed a prolonged survival time compared with the control group and the FA-M(PTX) was significantly more effective than pure paclitaxel and $\mathrm{M}(\mathrm{PTX})$.

As indicated, the growth of human esophageal EC9706 cancer xenografts in nu/nu mice was delayed after intravenous administration of conventional paclitaxel and polymeric paclitaxel micelles. Encouragingly, some mice experienced nearly complete regression of their xenograft after treatment with FA-M(PTX) at an equivalent paclitaxel dose of $20 \mathrm{mg} / \mathrm{kg}$, which implies that the composite FA-M(PTX) micelles were superior to paclitaxel and warrant further preclinical research as a promising agent in chemotherapy for esophageal cancer.

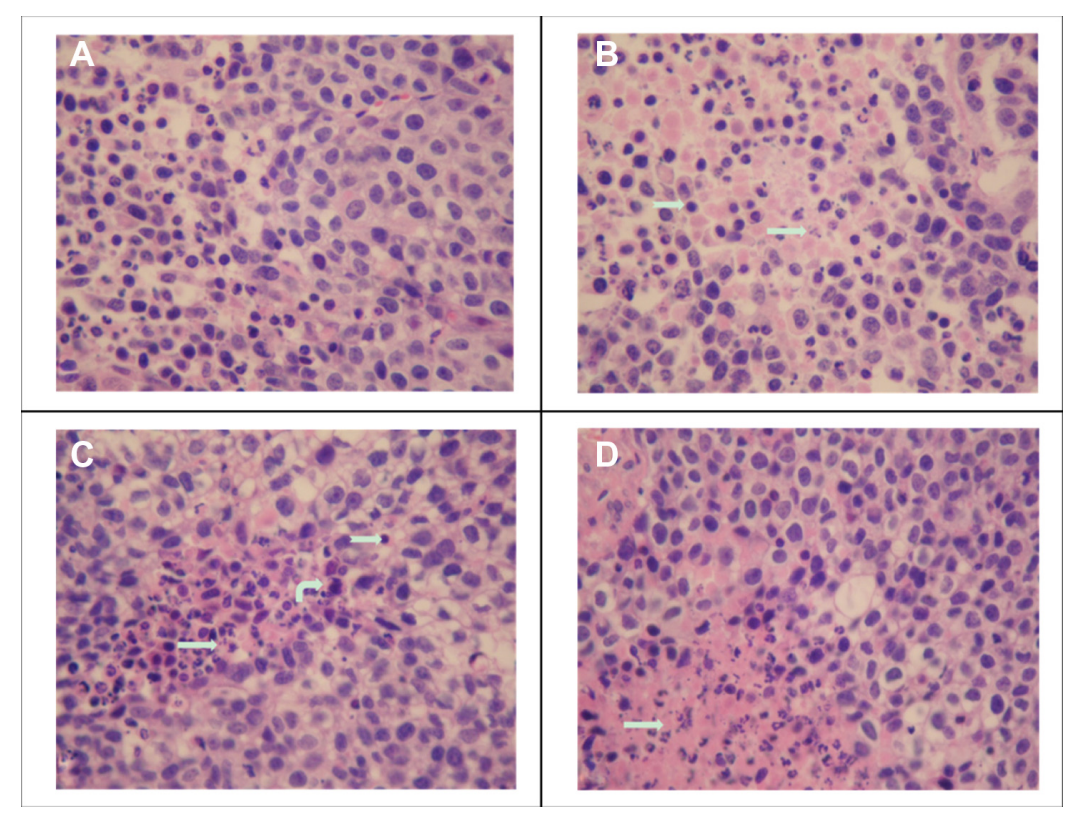

Figure 8 Tumor slices stained with hematoxylin and eosin. The slices were prepared from the margin of xenografts, and the necrotic area in the FA-M(PTX) group is significantly increased compared with that of the other groups. Straight arrows: tissue necrosis; curved arrows: macrophages; swallowtail arrows: lymphocytes. (A) Control, (B) PTX (C) M(PTX), and (D) FA-M(PTX).

Abbreviations: PTX, paclitaxel; M(PTX), paclitaxel-loaded micelles; FA-M(PTX), folate-targeted, paclitaxel-loaded micelles. 
A

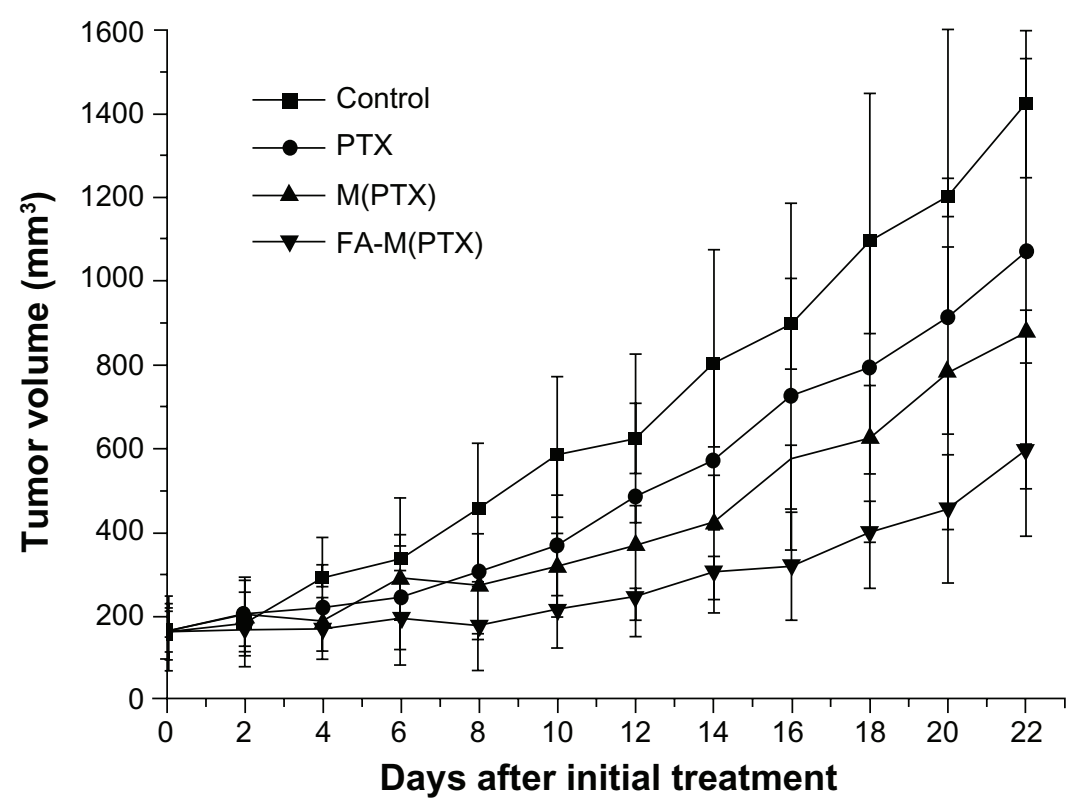

B

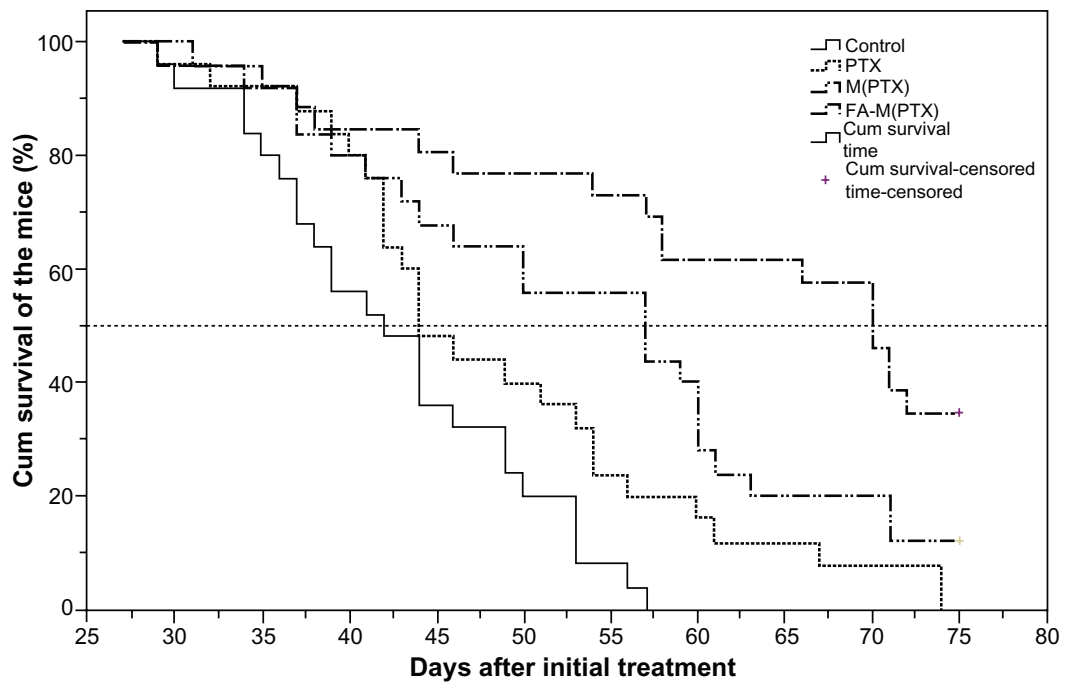

Figure 9 (A) Tumor volume change as a function of time after initial treatment in survival analysis; (B) Kaplan-Meier survival curves of human esophageal cancer xenograftbearing nude mice.

Abbreviations: PTX, paclitaxel; M(PTX), paclitaxel-loaded micelles; FA-M(PTX), folate-targeted, paclitaxel-loaded micelles

Table 2 Median and mean survival times for nude mice

\begin{tabular}{|c|c|c|c|c|c|}
\hline \multirow[t]{2}{*}{ Group } & \multirow[t]{2}{*}{$\mathbf{n}$} & \multicolumn{2}{|l|}{ Median survival time } & \multicolumn{2}{|l|}{ Mean survival time } \\
\hline & & Median \pm SD (days) & 95\% Cl (days) & Mean \pm SD (days) & 95\% Cl (days) \\
\hline Control山A & 25 & $42.0 \pm 2.5$ & $37.1-46.9$ & $42.8 \pm 1.6$ & $36.6-45.9$ \\
\hline PTX $*, \mathbf{\Lambda}$ & 25 & $44.0 \pm 1.9$ & $40.3-47.7$ & $48.7 \pm 2.3$ & $44.1-53.3$ \\
\hline $\mathrm{M}(\mathrm{PTX})^{* *, \mathbf{\Lambda}}$ & 25 & $57.0 \pm 5.8$ & $45.6-68.4$ & $54.2 \pm 2.6$ & $49.0-59.3$ \\
\hline FA-M(PTX)** & 26 & $70.0 \pm 2.5$ & $65.0-75.0$ & $62.2 \pm 3.0$ & $56.4-68.0$ \\
\hline
\end{tabular}

Notes: Log-rank test (Mantel-Cox): $* P<0.05(P=0.03) ; * * P<0.00$ I versus control; $\Delta P<0.05(P=0.025), \triangle \Delta P<0.00$ I, compared with FA-M(PTX); $P=0.078, P T X$ compared with M(PTX).

Abbreviations: $\mathrm{Cl}$, confidence interval; PTX, paclitaxel; SD, standard deviation; $\mathrm{n}$, number of mice; M(PTX), paclitaxel-loaded micelles; FA-M(PTX), folate-targeted, paclitaxel-loaded micelles. 
It should be noted that the paclitaxel formulations used in this study showed different orders of antitumor activity in vitro and in vivo. For free paclitaxel, in theory, the faster clearance of free paclitaxel from the body reduced the amount of drug entering cancer cells, while for nanoscale FA-M(PTX), enhanced antitumor efficacy was shown, which may be caused by the "shielding" effect of the PEG corona, combining with enhanced endocytosis efficiency after conjugation with folic acid.

\section{Conclusion}

FA-M(PTX) micelles with a spherical shape and a diameter of 40-60 nm were successfully prepared, in which the paclitaxel and folic acid content was $22.5 \mathrm{wt} \%$ and $1.4 \mathrm{wt} \%$, respectively. At a dose of $20 \mathrm{mg} / \mathrm{kg}$, FA-M(PTX) showed the best tumor inhibition efficacy in vivo compared with pure paclitaxel and M(PTX), which was mainly suggested by significantly inhibited growth of subcutaneous EC9706 xenografts and extended survival rate in tumor-bearing nude mice. This enhanced efficacy of FA-M(PTX) is most probably attributable to the targeted effect of folic acid on the micelles, verified by the preferential uptake of FA-M(RhB) compared with $\mathrm{M}(\mathrm{RhB})$ in EC9706 cells in folic acid-free medium, which could be competitively inhibited by free folic acid. Therefore, folic acid-mediated paclitaxel-loaded polymeric micelles could be promising for targeted chemotherapy in human esophageal cancer.

\section{Acknowledgments}

The authors acknowledge the financial support of the National Natural Science Foundation of China (20674084, 21004062, 51103148) and the Ministry of Science and Technology of China (973 Project 2009CB930102, 863 Project 2007AA03Z535).

\section{Disclosure}

The authors report no conflict of interest in this work.

\section{References}

1. Shahbaz Sarwar CM, Luketich JD, Landreneau RJ, Abbas G. Esophageal cancer: an update. Int J Surg. 2010;8(6):417-422.

2. Jemal A, Siegel R, Ward E, et al. Cancer statistics, 2009. CA Cancer J Clin. 2009;59(4):225-249.

3. Anderson LL, Lad TE. Autopsy findings in squamous-cell carcinoma of the esophagus. Cancer. 1982;50(8):1587-1590.

4. Chan KW, Chan EY, Chan CW. Carcinoma of the esophagus. An autopsy study of 231 cases. Pathology. 1986;18(4):400-405.

5. Cooper JS, Guo MD, Herskovic A, et al. Chemoradiotherapy of locally advanced esophageal cancer: long-term follow-up of a prospective randomized trial (RTOG 85-01). Radiation Therapy Oncology Group. JAMA. 1999;281(17):1623-1627.
6. Minsky BD, Pajak TF, Ginsberg RJ, et al. INT 0123 (Radiation Therapy Oncology Group 94-05) Phase III trial of combined-modality therapy for esophageal cancer: high-dose versus standard-dose radiation therapy. J Clin Oncol. 2002;20(5):1167-1174.

7. Ku GY, Ilson DH. Esophagogastric cancer: targeted agents. Cancer Treat Rev. 2010;36(3):235-248.

8. Malthaner R, Wong RK, Spithoff K. Preoperative or postoperative therapy for resectable oesophageal cancer: an updated practice guideline. Clin Oncol (R Coll Radiol). 2010;22(4):250-256.

9. Henry LR, Goldberg M, Scott W, et al. Induction cisplatin and paclitaxel followed by combination chemoradiotherapy with 5-fluorouracil, cisplatin, and paclitaxel before resection in localized esophageal cancer: a Phase II report. Ann Surg Oncol. 2006;13(2):214-220.

10. Jatoi A, Martenson J, Mahoney MR, et al. Results of a planned interim toxicity analysis with trimodality therapy, including carboplatin $\mathrm{AUC}=4$, paclitaxel, 5-fluorouracil, amifostine, and radiation for locally advanced esophageal cancer: preliminary analyses and treatment recommendations from the North Central Cancer Treatment Group. Int Semin Surg Oncol. 2004;1(1):9.

11. Meluch AA, Greco FA, Gray JR, et al. Preoperative therapy with concurrent paclitaxel/carboplatin/infusional 5-FU and radiation therapy in locoregional esophageal cancer: final results of a Minnie Pearl Cancer Research Network Phase II trial. Cancer J. 2003;9(4):251-260.

12. Seung SK, Smith JW, Molendyk J, et al. Selective dose escalation of chemoradiotherapy for esophageal cancer: role of treatment intensification. Semin Oncol. 2004;31(6 Suppl 18):13-19.

13. Urba SG, Orringer MB, Ianettonni M, et al. Concurrent cisplatin, paclitaxel, and radiotherapy as preoperative treatment for patients with locoregional esophageal carcinoma. Cancer. 2003;98(10):2177-2183.

14. Torchilin V. Tumor delivery of macromolecular drugs based on the EPR effect. Adv Drug Deliv Rev. 2011;63(3):131-135.

15. Hamaguchi T, Matsumura Y, Suzuki M, et al. NK105, a paclitaxelincorporating micellar nanoparticle formulation, can extend in vivo antitumour activity and reduce the neurotoxicity of paclitaxel. $\mathrm{Br} J$ Cancer. 2005;92(7):1240-1246.

16. Lee KS, Chung HC, Im SA, et al. Multicenter Phase II trial of Genexol-PM, a Cremophor-free, polymeric micelle formulation of paclitaxel, in patients with metastatic breast cancer. Breast Cancer Res Treat. 2008;108(2):241-250.

17. Chipman SD, Oldham FB, Pezzoni G, Singer JW. Biological and clinical characterization of paclitaxel poliglumex (PPX, CT-2103), a macromolecular polymer-drug conjugate. Int J Nanomedicine. 2006;1:375-383.

18. Yang D, Van S, Jiang X, Yu L. Novel free paclitaxel-loaded poly(L-gamma-glutamylglutamine)-paclitaxel nanoparticles. Int $J$ Nanomedicine. 2011;6:85-91.

19. Wang F, Chen Y, Zhang D, et al. Folate-mediated targeted and intracellular delivery of paclitaxel using a novel deoxycholic acid-Ocarboxymethylated chitosan-folic acid micelles. Int J Nanomedicine. 2012;7:325-337.

20. Werner ME, Karve S, Sukumar R, et al. Folate-targeted nanoparticle delivery of chemo- and radiotherapeutics for the treatment of ovarian cancer peritoneal metastasis. Biomaterials. 2011;32(33): $8548-8554$.

21. Lee RJ, Low PS. Folate-mediated tumor cell targeting of liposome-entrapped doxorubicin in vitro. Biochim Biophys Acta. 1995;1233(2):134-144.

22. Kamen BA, Smith AK. A review of folate receptor alpha cycling and 5-methyltetrahydrofolate accumulation with an emphasis on cell models in vitro. Adv Drug Deliv Rev. 2004;56(8):1085-1097.

23. Chen SZ, Liu XZ, Guo GH, et al. Research on expression of folate receptor alpha and its correlation with clinicopathology in esophageal carcinoma. Journal of Practical Oncology. 2008;23(3): 200-205.

24. Huang L, Hu J, Lang L, et al. Synthesis and characterization of electroactive and biodegradable ABA block copolymer of polylactide and aniline pentamer. Biomaterials. 2007;28(10):1741-1751. 
25. Tian HY, Deng C, Lin H, et al. Biodegradable cationic PEG-PEI-PBLG hyperbranched block copolymer: synthesis and micelle characterization. Biomaterials. 2005;26(20):4209-4217.

26. Deng C, Tian H, Zhang P, et al. Synthesis and characterization of RGD peptide grafted poly(ethylene glycol)-b-poly(L-lactide)-bpoly(L-glutamic acid) triblock copolymer. Biomacromolecules. 2006;7(2):590-596.

27. Lu T, Sun J, Chen X, et al. Folate-conjugated micelles and their folate-receptor-mediated endocytosis. Macromol Biosci. 2009;9(11):1059-1068.

28. Zhang X, Li Y, Chen X, et al. Synthesis and characterization of the paclitaxel/MPEG-PLA block copolymer conjugate. Biomaterials. 2005;26(14):2121-2128

29. Xie Z, Hu X, Chen X, et al. Synthesis and characterization of novel biodegradable poly(carbonate ester)s with photolabile protecting groups. Biomacromolecules. 2008;9(1):376-380.

30. Li Q, Zhu J, Sun F, et al. Oncostatin M promotes proliferation of ovarian cancer cells through signal transducer and activator of transcription 3 . Int J Mol Med. 2011;28(1):101-108.

31. Ma P, Liu S, Huang Y, et al. Lactose mediated liver-targeting effect observed by ex vivo imaging technology. Biomaterials. 2010;31(9): 2646-2654.

32. Zheng Y, Wan Y, Song X, et al. Composite micelles consisting of paclitaxel- and folic acid-carrying copolymers for treatment of Lewis lung cancer. J Control Release. 2011;152 Suppl 1:e123-e124.

33. Hattori Y, Maitani Y. Enhanced in vitro DNA transfection efficiency by novel folate-linked nanoparticles in human prostate cancer and oral cancer. J Control Release. 2004;97(1):173-183.

34. Zhao D, Zhao X, Zu Y, et al. Preparation, characterization, and in vitro targeted delivery of folate-decorated paclitaxel-loaded bovine serum albumin nanoparticles. Int J Nanomedicine. 2010;5:669-677.

35. Wehbrink D, Hassig M, Ritter N, et al. Immunohistochemical demonstration of cyclooxygenase-2 (COX-2) and prostaglandin receptors EP2 and FP expression in the bovine intercaruncular uterine wall around term. Anim Reprod Sci. 2008;106(3-4):241-254.
36. Yin C, Knudson CM, Korsmeyer SJ, Van Dyke T. Bax suppresses tumorigenesis and stimulates apoptosis in vivo. Nature. 1997;385(6617):637-640.

37. Jurgensmeier JM, Xie Z, Deveraux Q, et al. Bax directly induces release of cytochrome c from isolated mitochondria. Proc Natl Acad Sci USA. 1998;95(9):4997-5002.

38. Szumilo J, Chibowski DA. Assessment of the predictive value of clinical and histopathological factors as well as the immunoexpression of p53 and bcl-2 proteins in response to preoperative chemotherapy for esophageal squamous cell carcinoma. Dis Esophagus. 2000;13(3):191-197.

39. Kang SY, Han JH, Lee KJ, et al. Low expression of Bax predicts poor prognosis in patients with locally advanced esophageal cancer treated with definitive chemoradiotherapy. Clin Cancer Res. 2007;13(14):4146-4153.

40. Johnstone RW, Ruefli AA, Lowe SW. Apoptosis: a link between cancer genetics and chemotherapy. Cell. 2002;108(2):153-164.

41. Ismail N, Pihie AH, Nallapan M. Xanthorrhizol induces apoptosis via the up-regulation of Bax and p53 in HeLa cells. Anticancer Res. 2005;25(3B):2221-2227.

42. Hsia JY, Chen CY, Chen JT, et al. Prognostic significance of caspase-3 expression in primary resected esophageal squamous cell carcinoma. Eur J Surg Oncol. 2003;29(1):44-48.

43. Jiang H, Gong M, Cui Y, et al. Upregulation of caspase-3 expression in esophageal cancer correlates with favorable prognosis: an immunohistochemical study from a high incidence area in northern China. Dis Esophagus. 2010;23(6):487-492.

44. Salvesen GS. Caspases: opening the boxes and interpreting the arrows. Cell Death Differ. 2002;9(1):3-5.

45. Ghavami S, Hashemi M, Ande SR, et al. Apoptosis and cancer: mutations within caspase genes. J Med Genet. 2009;46(8):497-510.

46. Jersmann HP, Ross KA, Vivers S, et al. Phagocytosis of apoptotic cells by human macrophages: analysis by multiparameter flow cytometry. Cytometry A. 2003;51(1):7-15. 


\section{Suplementary table}

Table SI Characteristics of M(PTX) and FA-M(PTX)

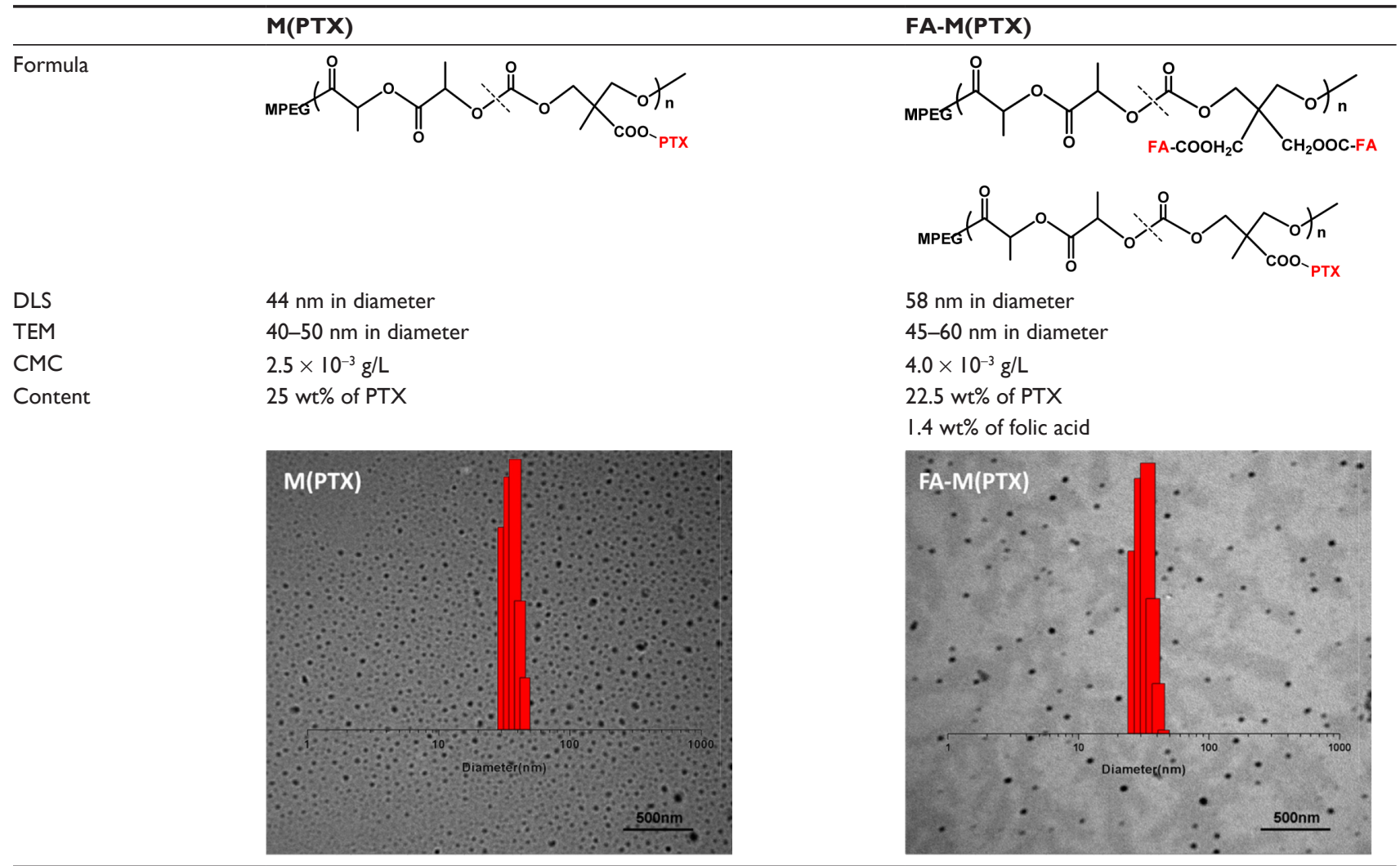

Abbreviations: PTX, paclitaxel; M(PTX), paclitaxel-loaded micelles; FA-M(PTX), folate-targeted, paclitaxel-loaded micelles; DLS, dynamic light scattering; TEM, transmission electron microscopy; CMC, critical micelle concentration.

\section{Publish your work in this journal}

The International Journal of Nanomedicine is an international, peerreviewed journal focusing on the application of nanotechnology in diagnostics, therapeutics, and drug delivery systems throughout the biomedical field. This journal is indexed on PubMed Central, MedLine, CAS, SciSearch $\AA$, Current Contents ${ }^{\circledR} /$ Clinical Medicine,
Journal Citation Reports/Science Edition, EMBase, Scopus and the Elsevier Bibliographic databases. The manuscript management system is completely online and includes a very quick and fair peer-review system, which is all easy to use. Visit http://www.dovepress.com/ testimonials.php to read real quotes from published authors. 